\title{
Mutant Prevention Concentration Siprofloksasin terhadap Escherichia coli Patogen dari Usap Kloaka Broiler Secara In Vitro
}

\section{In Vitro Mutant Prevention Concentration of Ciprofloxacin on Pathogenic Escherichia coli from Broiler Cloacal Swab}

\author{
Maria Fatima Palupi, Eli Nugraha, Meutia Hayati, Neneng Atikah \\ Balai Besar Pengujian Mutu dan Sertifikasi Obat Hewan-Kementerian Pertanian \\ Jalan Raya Pembangunan Gunungsindur, Bogor \\ Email: lupi_ima@yahoo.co.id
}

Naskah diterima: 19 Juni 2020, direvisi: 18 Desember 2020, disetujui: 23 Desember 2020

\begin{abstract}
Mutant prevention concentration (MPC) is an in vitro test used to determine the lowest drug concentration needed to inhibit the growth of a single-step-mutant bacterial subpopulation. The purpose of this study was to determine the MPC value of ciprofloxacin against pathogenic Escherichia coli to obtained the range of mutant selection windows (MSW) of ciprofloxacin. Ciprofloxacin is a quinolone group that is included in the Highest Priority Critically Important Antimicrobials for Human Medicine but is also used for the treatment of bacterial infections in production animals. Twenty-four of pathogenic $E$. coli isolates sensitive to ciprofloxacin were tested to obtain MPC values and minimum inhibitory concentration (MIC) values. Test the MPC and MIC values to get the MSW range is done by the method of agar dilution. Mueller-Hinton agar containing standard ciprofloxacin was inoculated with $10^{10} \mathrm{cfu} E$. coli for the MPC test and $10^{4} \mathrm{cfu}$ for the MIC test. Based on the MPC test results, the MPC value of ciprofloxacin was 4-64 $\mu \mathrm{g} / \mathrm{mL}(22.96 \pm 19.07 \mu \mathrm{g} / \mathrm{mL})$ and there was one isolate which had an MPC $>256 \mu \mathrm{g} / \mathrm{mL}$. These results showed a wide range of MSW with a lower limit of the MIC value of 0.25 $-2 \mu \mathrm{g} / \mathrm{mL}(0.55 \pm 0.37 \mu \mathrm{g} / \mathrm{mL})$ to the upper limit of the MPC value of 4-64 $\mu \mathrm{g} / \mathrm{mL}(22.96 \pm 19.07 \mu \mathrm{g} / \mathrm{mL})$. Based on the results of this MPC assessment it can be concluded that the dose of ciprofloxacin in production animals has a wide range of MSW that is allow for single-step mutants.
\end{abstract}

Keywords : ciprofloxacin; E. coli; MPC; MSW

\begin{abstract}
Abstrak
Mutant prevention concentration (MPC) merupakan uji in vitro yang digunakan untuk menentukan konsentrasi obat terendah yang diperlukan untuk menghambat pertumbuhan subpopulasi bakteri single-stepmutant. Tujuan penelitian ini adalah untuk mengetahui nilai MPC siprofloksasin sehingga didapatkan rentang mutant selection windows (MSW) dari siprofloksasin terhadap Escherichia coli patogen yang peka terhadap siprofloksasin. Siprofloksasin merupakan golongan kuionolon yang masuk dalam Highest Priority Critically Important Antimicrobials for Human Medicine akan tetapi juga digunakan untuk terapi infeksi bakteri di hewan produksi. Sebanyak 24 isolat $E$. coli patogen peka terhadap siprofloksasin diuji untuk mendapatkan nilai MPC dan nilai konsentrasi hambat minimum (KHM). Uji nilai MPC dan KHM untuk mendapatkan rentang MSW dilakukan dengan metode agar dilution. Agar Mueller-Hinton yang mengandung standar siprofloksasin diinokulasi dengan $10^{10} \mathrm{cfu}$ E. coli untuk uji MPC dan $10^{4} \mathrm{cfu}$ untuk uji KHM. Berdasarkan hasil uji MPC didapatkan nilai MPC siprofloksasin 4-64 $\mu \mathrm{g} / \mathrm{mL}(22.96 \pm 19.07 \mu \mathrm{g} / \mathrm{mL})$ dan terdapat satu isolat yang memiliki MPC $>256 \mu \mathrm{g} / \mathrm{mL}$. Hasil ini memberikan rentang MSW yang luas yaitu dengan batas bawah nilai KHM $0.25-2 \mu \mathrm{g} / \mathrm{mL}(0.55$ $\pm 0.37 \mu \mathrm{g} / \mathrm{mL})$ hingga batas atas 4-64 $\mu \mathrm{g} / \mathrm{mL}(22.96 \pm 19.07 \mu \mathrm{g} / \mathrm{mL})$. Berdasarkan hasil pengkajian MPC ini dapat disimpulkan dapat bahwa dosis pemberian siprofloksasin pada hewan produksi memiliki rentang MSW yang cukup lebar sehingga memungkinkan timbulnya single-step-mutant.
\end{abstract}

Kata kunci : ciprofloxacin; E. coli; MPC; MSW 


\section{Pendahuluan}

Jumlah kasus resistansi antimikroba, khususnya resistansi antibiotik, secara global cenderung meningkat setiap tahunnya. Salah satu penyebab berkembangnya resistansi menurut Gebru et al. (2011) adalah penggunaan antibiotik pada konsentrasi terapi yang berdasarkan nilai Konsentrasi Hambat Minimum (KHM). Nilai KHM didefinisikan sebagai konsentrasi terendah dari suatu agen antibiotik untuk mencegah pertumbuhan populasi infeksi bakteri yang diansumsikan tidak ada mutasi (Gianvecchio et al. 2019). Nilai KHM sering kali digunakan untuk menentukan resistansi dari suatu antibiotik. Dalam menentukan nilai KHM, metode uji yang sering digunakan adalah agar dilution dan broth micro dilution. Nilai KHM dengan menggunakan metode agar dilution ditentukan menggunakan inokulasi bakteri sebanyak $10^{4} \mathrm{cfu}$ per titik, sedangkan untuk broth micro dilution menggunakan inokulasi sebanyak $5 \times 10^{4}$ cfu per well (CLSI 2016). Konsentrasi inokulasi bakteri sejumlah $10^{4}$ cfu dalam uji KHM, tidak dapat digunakan untuk mendeteksi perkembangan subpopulasi bakteri resistan dalam konsentrasi infeksi bakteri yang mencapai $10^{6}-10^{8} \mathrm{cfu}$ atau lebih (Blondeau 2009; Hindler dan Humphries 2013). Oleh sebab itu, konsentrasi terapi yang ditentukan berdasarkan nilai KHM dapat mengeliminasi atau menghambat pertumbuhan bakteri yang peka, akan tetapi, disisi lain, secara selektif akan memperbanyak bakteri mutan resistan (Gebru et al. 2011).

Sejalan dengan pemberian antibiotik pada hewan untuk mengobati infeksi bakteri, jumlah koloni bakteri infeksi akan menurun, akan tetapi terdapat sejumlah kecil koloni yang mampu bertahan karena mutasi spontan setelah terpapar antibiotik pada dosis KHM yang disebut sebagai resistansi mutan single-step (Gianvecchio et al. 2019). Adapun menurut Drlica (2003) mutasi single-step adalah mutasi yang mampu mengurangi kepekaan suatu organisme terhadap suatu antibiotik sedemikian rupa sehingga pada dosis sebagai terapi tidak dapat lagi mencegah pertumbuhan mutan. Berkenaan dengan mekanisme timbulnya resistansi ini, maka dilakukan evaluasi resistansi antibiotik dengan menggunakan hipotesis rentang mutant selection window (MSW). Rentang MSW adalah konsentrasi obat yang berada diantara nilai
KHM yang menjadi batas bawah MSW dan nilai mutant prevention concentration (MPC) yang menjadi batas atas MSW. Dalam rentang MSW, pertumbuhan bakteri yang peka akan dihambat, akan tetapi pertumbuhan bakteri mutan tidak bisa dihambat (Gebru et al. 2011)

Mutant prevention concentration adalah konsentrasi obat, dalam hal ini antibiotik, yang diperlukan untuk mencegah pertumbuhan mutasi single step pada populasi bakteri yang peka pada konsentrasi yang tinggi atau $10^{10} \mathrm{cfu}$ atau lebih (Marcusson et al. 2005; Mouton et al. 2005; Gianvecchio et al. 2019). Pengujian MPC selalu dilakukan dengan menggunakan metode agar dilution (Blondeau 2009). Nilai MPC digunakan sebagai perkiraan ukuran potensi antibiotik untuk memungkinkan seleksi resistan selama pengobatan pasien yang terinfeksi (Choi dan Ko et al. 2014). Guna mencegah adanya bakteri resistan berkenaan dengan mutasi single step yang berhubungan dengan pemberian antibiotik, maka sangat diperlukan data nilai KHM, MPC, dan MSW.

Siprofloksasin merupakan antibiotik golongan kuinolon. Kuinolon sangat penting bagi kesehatan manusia. Badan Kesehatan Dunia telah memasukkan kuniolon dalam Highest Priority Critically Important Antimicrobials for Human Medicine bersama dengan sefalosporin (generasi ke-3, 4, dan 5), glikopeptid, makrolid, polimiksin, dan ketolide (WHO 2017). Selain digunakan pada manusia, siprofloksasin di Indonesia diperbolehkan untuk digunakan di hewan produksi sebagai terapi infeksi bakteri. Berdasarkan Indeks Obat Hewan Indonesia Edisi IX (DJPKH 2016) terdapat 22 nama dagang obat hewan yang mengandung siprofloksasin.

Berkenaan dengan pentingnya siprofloksasin pada manusia dan hewan maka diperlukan data lengkap mengenai KHM, MSW, dan MPC mengenai siprofloksasin. Tujuan penelitian ini adalah untuk mengetahui nilai MPC siprofloksasin terhadap isolat $E$. coli patogen yang berasal dari swab (usap) kloaka broiler hidup.. Berdasarkan nilai KHM dan MPC akan didapatkan rentang MSW dari siprofloksasin terhadap E. coli patogen. Data ini merupakan informasi yang penting untuk mengevaluasi kemungkinan dosis siprofloksasin yang digunakan pada hewan masih bisa menimbulkan single step mutan resistan. 


\section{Materi dan Metode}

Penelitian dilakukan pada bulan November 2019 hingga April 2020. Penelitian dilaksanakan di Unit Uji Farmasetik dan Premiks-Balai Besar Pengujian Mutu dan Sertifikasi Obat Hewan (BBPMSOH).

\section{Seleksi Isolat Escherichia coli untuk Uji Mutant Prevention Concentration Siprofloksasin}

Uji in vitro MPC hanya dapat dilakukan dengan menggunakan isolat bakteri yang masih peka terhadap antibiotik yang akan diuji (Blondeau 2009). Seleksi kandidat isolat yang digunakan untuk uji MPC siprofloksasin adalah arsip isolat E. coli BBPMSOH sebanyak 159 isolat. Arsip isolat yang digunakan diisolasi dari sampel usap kloaka ayam broiler dari 48 kandang broiler dari 7 provinsi yang dilakukan pada tahun 2019. Tiap kandang diambil 5 ekor ayam untuk diambil sampel usap kloaka, kemudian dipool dalam satu wadah yang berisi $0.1 \%$ Phosphate Buffer Solution (PBS, Oxoid-UK). Tiap pool kemudian diambil satu ose dan diinokulasikan ke agar Eosin Methylene Blue (EMB, (Oxoid-UK) kemudian diinkubasi pada suhu $35^{\circ} \mathrm{C}$ selama $24 \mathrm{jam} \pm 2 \mathrm{jam}$. Koloni tunggal tipikal E. coli berwarna keemasan, dan dari taip pool diambil 3-5 koloni tunggal. Tiap koloni dipurifikasi dan kemudian dilanjutkan ke uji biokimia sesuai dengan SNI 2897 (2008).

Guna mendapatkan isolat kandidat untuk uji MPC dilakukan uji kepekaan siprofloksasin untuk mendapatkan nilai KHM siprofloksasin terhadap E. coli . Uji nilai KHM dilakukan menggunakan metode agar dilution (CLSI 2016), adapun untuk uji patogesitas E. coli dilakukan dengan menggunakan uji Congo Red (Berkhoff dan Vinal 1986). Media yang digunakan adalah agar Muller Hinton (MHA) (Difco/DB-FRA) yang mengandung standar siprofloksasin (Sigma-USA) dengan konsentrasi pengenceran kelipatan dua. Konsentrasi standar siprofloksasin dalam media MHA dari $0.25 \mu \mathrm{g} / \mathrm{mL}$ hingga $64 \mu \mathrm{g} / \mathrm{mL}$. Sebagai isolat kontrol positif digunakan E. coli ATCC 25922 dan MHA tanpa standar digunakan sebagai kontrol media (CLSI 2016).

Isolat $E$. coli yang akan diuji ditanam di media nutrient agar (NA, DIFCO/DB-FRA) atau heart infusion agar (HIA, DIFCO/DB-FRA) dan dinkubasi pada suhu $35-37{ }^{\circ} \mathrm{C}$ selama 18 jam. Uji kepekaan dilakukan dengan mengambil 1-2 koloni E. coli yang tumbuh di NA atau HIA dan kemudian diinokulasi ke dalam heart infusion broth (HIB, DB/Difco-FRA). Media HIB yang telah diinokulasi kemudian diinkubasi selama 2-6 jam pada suhu $35-37{ }^{\circ} \mathrm{C}$ hingga kekeruhannya setara dengan standar McFarland $0.5 \%$. E. coli dalam HIB kemudian diencerkan dengan menggunakan $\mathrm{NaCl}$ fisiologis steril dan diinokulasikan 1-2 $\mu \mathrm{L}$ atau setara $10^{4}$ cfu ke media MHA yang telah mengandung siprofloksasin. Media MHA yang telah diinokulasi kemudian diinkubasi selama 18-24 jam pada suhu $35-37{ }^{\circ} \mathrm{C}$. Isolat dinyatakan resistan terhadap siprofloksasin jika memiliki nilai $\mathrm{KHM} \geq 4 \mu \mathrm{g} / \mathrm{mL}$ (CLSI 2016).

Uji patogenesitas dilakukan dengan menggunakan uji Congo Red. Isolat E. coli ditanam pada media Congo Red dan diinkubasi selama 24 jam pada suhu $35-37{ }^{\circ} \mathrm{C}$ dan dilanjutkan pada suhu ruangan selama $48 \mathrm{jam}$. Isolat dinyatakan patogen jika pada hari ketiga warna koloni isolat menunjukkan warna merah. Uji KHM dan patogenesitas tiap isolat masing-masing diulang tiga kali. Isolat dinyatakan layak menjadi kandidat uji MPC jika memiliki nilai $\mathrm{KHM}<4 \mu \mathrm{g} / \mathrm{mL}$ dan bersifat patogen.

\section{Uji Mutant Prevention Concentration Sipro- floksasin}

Penentuan nilai MPC siprofloksasin dilakukan dengan menggunakan metode agar dilution. Isolat $E$. coli peka siprofloksasin-patogen diinokulasikan ke tiga cawan petri media heart infusion agar (HIA, DB/Difco-FRA) dan kemudian diinkubasi selama 18-24 jam pada suhu $35-37{ }^{\circ} \mathrm{C}$. Semua E. coli yang tumbuh pada cawan petri kemudian diambil dengan menggunakan kapas steril dan dipindahkan ke tabung yang berisi $100 \mathrm{~mL}$ Mueller-Hinton broth (MHB, DB/Difco-FRA). Media MHB yang telah diinokulasi kemudian diinkubasi selama 18-24 pada suhu 35-37 ${ }^{\circ} \mathrm{C}$. Setelah inkubasi, MHB kemudian disentrifus dengan kecepatan $5000 \mathrm{x}$ g selama 30 menit pada suhu $4{ }^{\circ} \mathrm{C}$. Pellet yang terbentuk kemudian dilarutkan dalam $3 \mathrm{~mL}$ MHB. Uji nilai MPC dilakukan dengan menginokulasikan $100 \mu \mathrm{L}$ MHB yang mengandung $10^{10} \mathrm{cfu} E$. coli ke MHA yang mengandung standar siprofloksasin (Sigma- 
USA) dengan pengenceran kelipatan dua kali dari konsentrasi $0.5 \mu \mathrm{g} / \mathrm{mL}$ hingga $256 \mu \mathrm{g} / \mathrm{mL}$. Media MHA yang sudah diinokulasi kemudian diinkubasi selama 24 jam pada suhu $37{ }^{\circ} \mathrm{C}$ (Blondeau 2009; Gebru et al. 2011). Hasil uji MPC dianalisa secara deskriptif dan evaluasi terhadap farmakokinetik siprofloksasin dilakukan dengan menggunakan berbagai kajian farmakokinetik siprofloksasin pada unggas yang sudah dipublikasikan.

\section{Hasil dan Pembahasan}

Berdasarkan hasil uji seleksi kandidat E. coli untuk uji MPC dari 159 isolat E. coli didapatkan 24 isolat $E$. coli patogen yang peka terhadap siprofloksasin. Isolat $E$. coli dinyatakan masih peka terhadap siprofloksasin apabila isolat tidak bisa tumbuh pada media MHA yang mengandung siprofloksasin $2 \mu \mathrm{g} / \mathrm{mL}$ atau memiliki KHM < $4 \mu \mathrm{g} / \mathrm{mL}$ (Gambar 1). Isolat E. coli dinyatakan patogen jika setelah 3 hari inkubasi pada suhu ruangan, isolat yang tumbuh di media Congo Red menunjukkan koloni warna merah (Gambar 2). Nilai KHM dari 24 isolat $E$. coli tersebut ada lah $0.25-2 \mu \mathrm{g} / \mathrm{mL}$ sebagaimana tersaji dalam Tabel 1.

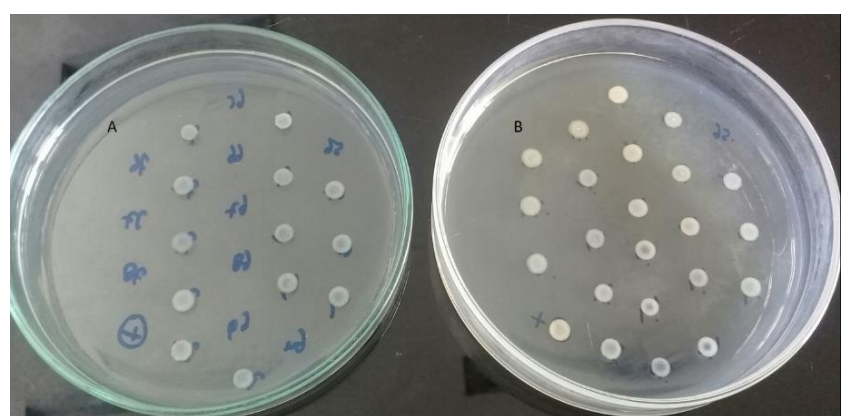

Gambar 1 Hasil uji KHM siprofloksasin terhadap E. coli dengan menggunakan metode agar dilution. (A) Isolat $E$. coli diinokulasikan pada media MHA yang mengandung siprofloksasin $2 \mu \mathrm{g} / \mathrm{mL}$, E. coli yang tidak tumbuh dinyatakan masih peka dan yang tumbuh dinyatakan resistan karena berarti memiliki $\mathrm{KHM} \geq 4 \mu \mathrm{g} / \mathrm{mL}$. (B) Hasil pertumbuhan isolat-isolat E. coli yang sama dengan cawan petri A diinokulasikan pada media MHA yang tidak mengandung siprofloksasin sebagai kontrol.

Berdasarkan hasil uji MPC pada Tabel 1 dan Gambar 3, dari 24 isolat yang diuji didapatkan nilai MPC dari $4 \mu \mathrm{g} / \mathrm{mL}$ hingga $>256 \mu \mathrm{g} / \mathrm{mL}$. Sebanyak 2 isolat $(8.33 \%)$ mempunyai nilai MPC $4 \mu \mathrm{g} / \mathrm{mL}, 5$ isolat $(20.83 \%)$ dengan nilai MPC 8

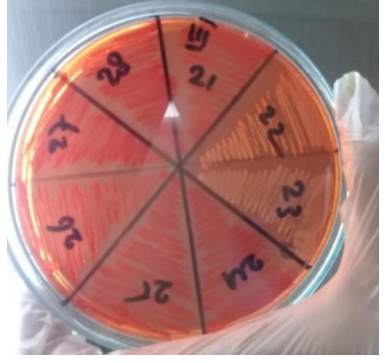

Gambar 2 Hasil uji patogenesitas dengan menggunakan Congo Red. Isolat patogen tumbuh setelah inkubasi ditandai dengan koloni warna merah dan isolat komensal/ non patogen berwarna putih

$\mu \mathrm{g} / \mathrm{mL}, 8$ isolat (33.33\%) dengan nilai MPC 16 $\mu \mathrm{g} / \mathrm{mL}, 5$ isolat (20.83\%) menunjukkan nilai MPC $32 \mu \mathrm{g} / \mathrm{mL}, 3$ isolat (12.5\%) memiliki nilai MPC $64 \mu \mathrm{g} / \mathrm{mL}$, dan 1 isolat $(8.17 \%)$ menunjukkan nilai MPC siprofloksasin $>256 \mu \mathrm{g} / \mathrm{mL}$. Semua nilai MPC siprofloksasin yang dihasilkan dari 24 isolat tersebut berada di atas nilai batas resistansi E. coli terhadap siprofloksasin ( $\geq 4 \mu \mathrm{g} / \mathrm{mL}$ ) yang ditentukan berdasarkan nilai KHM. Hasil nilai KHM, MPC, dan Mutant Prevention Index (MPI) atau rasio antara KHM dan MPC disajikan pada Tabel 1.

Hasil dalam Tabel 1 menunjukkan nilai MPI adalah 8 hingga $\geq 128$ atau nilai MPC yang dihasilkan dari isolat-isolat tersebut 8-128 kali lebih tinggi dari nilai KHM. Bahkan terdapat satu isolat yang memiliki nilai MPI $>128$. Nilai MPI paling rendah adalah 4 yang berasal dari isolat $E$. coli kode 103 dan 145. Nilai MPI siprofloksasin E. coli kode 103 tetap tinggi, karena memerlukan 8 kali konsentrasi KHM siprofloksasin untuk mencegah adanya pertumbuhan koloni bakteri mutan resistan dari isolat $E$. coli 103 . Adapun untuk isolat $E$. coli kode 145 diperlukan konsentrasi KHM hingga 16 kali untuk mencegah single step mutan. Berdasarkan hasil uji KHM dan MPC siprofloksasin didapatkan rentang konsentrasi MSW yang bervariasi. Batas bawah MSW dengan nilai KHM paling rendah adalah $0.25 \mu \mathrm{g} / \mathrm{mL}$ dan batas atas tertinggi dengan nilai MPC $>256 \mu \mathrm{g} / \mathrm{mL}$.

MPC merupakan salah satu parameter farmakodinamik yang dapat sangat berguna untuk menentukan dosis antibiotik yang akan digunakan untuk mencegah munculnya mutan single step bakteri resistan. Nilai MPC siprofloksasin terhadap 23 isolat $E$. coli peka siprofloksasin-patogen adalah 4-64 $\mu \mathrm{g} / \mathrm{mL}(22.96 \pm 19.07 \mu \mathrm{g} /$ 
Tabel 1 Nilai KHM, MPC, dan MPI siprofloksasin terhadap E. coli patogen dari usap kloaka broiler hidup

\begin{tabular}{|c|c|c|c|c|}
\hline No. & Kode isolat $E$. coli & $\mathrm{KHM}(\mu \mathrm{g} / \mathrm{mL})$ & $\mathrm{MPC}(\mu \mathrm{g} / \mathrm{mL})$ & MPI \\
\hline 1 & 1 & 0.5 & 16 & 32 \\
\hline 2 & 6 & 1 & 32 & 32 \\
\hline 3 & 9 & 1 & 16 & 16 \\
\hline 4 & 21 & 2 & $>256$ & $>128$ \\
\hline 5 & 54 & 0.5 & 16 & 32 \\
\hline 6 & 64 & 0.5 & 8 & 16 \\
\hline 7 & 65 & 0.5 & 64 & 128 \\
\hline 8 & 66 & 0.5 & 16 & 32 \\
\hline 9 & 67 & 0.5 & 8 & 16 \\
\hline 10 & 68 & 0.5 & 32 & 64 \\
\hline 11 & 69 & 0.5 & 16 & 32 \\
\hline 12 & 85 & 0.5 & 64 & 128 \\
\hline 13 & 86 & 0.5 & 16 & 32 \\
\hline 14 & 89 & 0.5 & 8 & 16 \\
\hline 15 & 91 & 0.5 & 64 & 128 \\
\hline 16 & 98 & 0.5 & 32 & 64 \\
\hline 17 & 99 & 0.5 & 16 & 32 \\
\hline 18 & 103 & 0.5 & 4 & 8 \\
\hline 19 & 121 & 0.5 & 32 & 64 \\
\hline 20 & 143 & 0.25 & 16 & 64 \\
\hline 21 & 144 & 0.25 & 8 & 32 \\
\hline 22 & 145 & 0.25 & 4 & 16 \\
\hline 23 & 146 & 0.25 & 8 & 32 \\
\hline 24 & 147 & 0.25 & 32 & 128 \\
\hline
\end{tabular}

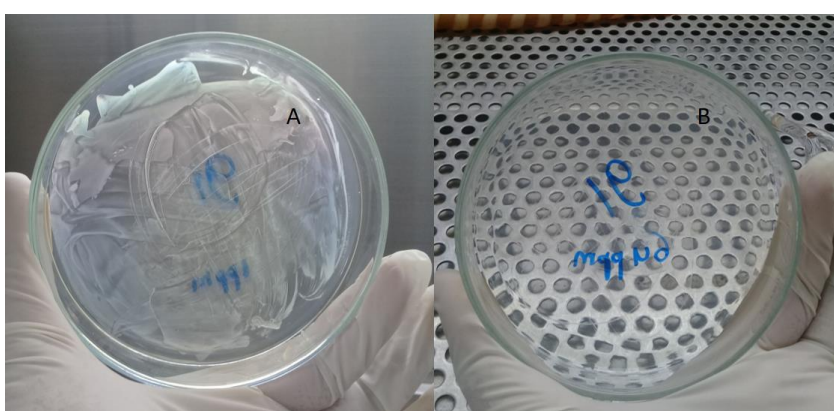

Gambar 3 Hasil uji nilai MPC siprofloksasin isolat Escherichia coli kode 91.

Keterangan: (A) Terdapat pertumbuhan mutasi single step di media MHA konsentrasi siprofloksasin 16 $\mu \mathrm{g} / \mathrm{mL}$. (B) Tidak ada pertumbuhan di media MHA dengan konsentrasi siprofloksasin $64 \mu \mathrm{g} / \mathrm{mL}$

$\mathrm{mL})$. Adapun terdapat satu isolat yang memiliki MPC $>256 \mu \mathrm{g} / \mathrm{mL}$. Berdasarkan nilai KHM dan MPC dari 23 isolat yang memberikan nilai MPC 4-64 $\mu \mathrm{g} / \mathrm{mL}$, maka didapatkan rentang MSW siprofloksasin terhadap E. coli patogen adalah dengan batas bawah $0.25-2 \mu \mathrm{g} / \mathrm{mL}(0.55 \pm 0.37$ $\mu \mathrm{g} / \mathrm{mL})$ dan batas atas adalah 4-64 $\mu \mathrm{g} / \mathrm{mL}(22.96$ $\pm 19.07 \mu \mathrm{g} / \mathrm{mL})$. Sedangkan satu isolat E. coli dengan kode 21 memiliki rentang MSW 2 hingga $>256 \mu \mathrm{g} / \mathrm{mL}$.

Hasil KHM, MPC, MPI, dan WSW siprofloksasin sangat bervariasi tergantung dari reaksi tiap isolat bakteri terhadap konsentrasi obat (Randall et al. 2004; Hansen et al. 2005; Marcusson et al. 2005; Daoud et al. 2014; Gianvecchio et al. 2019). Penelitian Daoud et al. (2014) menggunakan isolat E. coli dan Klebsiella yang diisolasi dari saluran urinaria dan dari kedua isolat tersebut didapatkan rentang nilai MSW 2-12 $\mu \mathrm{g} / \mathrm{mL}$. Randall et al. (2004) melakukan evaluasi MPC siprofloksasin terhadap Salmonella Enteritidis dan $S$. Typhimurium. Dari hasil penelitiannya didapatkan nilai KHM untuk $S$. Enteritidis berkisar 0.03-5 $\mu \mathrm{g} / \mathrm{mL}$, MPC $0.25-4 \mu \mathrm{g} / \mathrm{mL}$, dan MPI yang didapatkan adalah 2-32. Adapun dari penelitian Gianvecchio et al. (2019) didapatkan rata-rata 
MPC siprofloksasin terhadap Staphylococcus epidermidis adalah $1.2 \mu \mathrm{g} / \mathrm{mL}$. Hasil MPC sangat bervariasi karena tergantung dari kemampuan munculnya mutasi spontan dari tiap isolat terutama fase munculnya mutasi spontan. Apabila mutasi terjadi pada awal pertumbuhan populasi bakteri, maka jumlah sel yang mengalami mutasi akan lebih banyak. Akan tetapi, jika mutasi terjadi belakangan, maka jumlah sel yang mutasipun akan lebih rendah (Gianvecchio et al. 2019).

Guna mendapatkan korelasi antara farmakokinetik dan nilai KHM, MSW, dan MPC pada hewan produksi maka perlu dilakukan evaluasi dengan menggunakan data farmakokinetik siprofloksasin pada broiler. Karakteristik farmakokinetik-farmakodinamik dalam menentukan aktivitas antibakteri dan menghambat laju resistan siprofloksasin adalah menggunakan rasio Area Under Curve (AUC) dan nilai KHM (Blondeau 2009; Khan et al. 2015). Evaluasi KHM, MSW, dan MPC dengan data farmakokinetik menggunakan data berbagai penelitian farmakokinetik siprofloksasin pada broiler, antara lain data farmakokinetik dengan pemberian dosis peroral $8 \mathrm{mg} / \mathrm{kg} \mathrm{BB}$ (Anadón et al.2001), farmakokinetik siprofloksasin pada broiler yang diberi dosis $50 \mathrm{mg} / \mathrm{kg} \mathrm{BB}$ secara intravena (Ambarwati, 2014), dan data farmakokinetik siprofloksasin dengan dosis $10 \mathrm{mg} /$ $\mathrm{kg} \mathrm{BB}$ peroral atau intraingluvial (Ivanova et al. 2017). Data parameter farmakokinetik ketiga penelitian tersebut tersaji pada Tabel 2 .

Sebagaimana tersaji dalam Tabel 2, nilai AUC siprofloksasin yang diberikan secara peroral pada dosis $8 \mathrm{mg} / \mathrm{kg}$ BB serta $10 \mathrm{mg} / \mathrm{BB}$ berada di atas rata-rata nilai KHM dan di bawah rata-rata nilai MPC siprofloksasin terhadap E. coli yang diuji. Sedangkan AUC pada pemberian IV dengan dosis $50 \mathrm{mg} / \mathrm{kg}$ BB berada diatas rata-rata nilai MPC, akan tetapi nilai AUC dosis tersebut masih di bawah batas atas rentang MPC yaitu $42.03 \mu \mathrm{g} / \mathrm{mL}$. Adapun Cmaks dari data farmakokinetik semuanya berada di atas rata-rata nilai KHM dan di bawah rata-rata nilai MPC. Oleh sebab itu, nilai AUC dan Cmaks siprofloksasin ketiga dosis tersebut masuk ke dalam rentang MSW siprofloksasin terhadap $E$. coli. Informasi ini sangat penting karena hal ini menunjukkan bahwa pada dosis tersebut masih memungkinkan terjadinya single step mutant. Hal ini disampaikan oleh Cai et al. (2010), apabila konsentrasi antibiotik masih di dalam rentang MSW, maka subpopulasi mutan resistan dapat berkembang.

Guna mendapatkan efek pengobatan yang memuaskan dan untuk mengurangi munculnya bakteri resistan selama pengobatan, maka nilai rasio AUC/KHM yang diharapkan adalah > 125 (Blondeau 2009). Berkenaan penggunaan sipfloksasin pada broiler di Indonesia mayoritas diberikan melalui air minum, maka, evaluasi AUC/ KHM dilakukan dengan menggunakan data AUC hasil penelitian Anadón et al. (2001) dan Ivanova et al. (2017). Berdasarkan nilai AUC penelitian Anadón et al. (2001) didapatkan rentang rasio AUC/KHM dari 24 isolat E. coli yang diuji adalah $6.12-48.84(27.73 \pm 12.32)$. Adapun dari data AUC penelitian Ivanova et al. (2017) didapatkan rentang rasio AUC/KHM 5.99 - 47.88 (27.18 \pm 12.08). Hasil ini menunjukkan bahwa nilai AUC/ KHM dari 24 isolat $E$. coli yang diuji lebih rendah dari rasio yang diharapkan sehingga masih bisa memunculkan mutan single step.

Pendekatan nilai MPC dapat digunakan sebagai metode alternatif untuk mengurangi munculnya bakteri resistan akibat mutasi single step dari subpopulasi bakteri resistan. Berdasarkan penelitian MPC ini, didapatkan nilai MSW dan MPI siprofloksasin yang sangat penting untuk melihat kemungkinan munculnya mutasi dari dosis yang diberikan. Tingginya nilai MPC menghasilkan rentang MSW siprofloksasin yang lebar yaitu antara $0.55 \pm 0.37 \mu \mathrm{g} / \mathrm{mL}-22.96 \pm$ $19.07 \mu \mathrm{g} / \mathrm{mL}$ (batas atas MSW). Lebarnya rentang MSW juga didukung dengan nilai MPI. Nilai MPI siprofloksasin tunggal terhadap E. coli bervariasi antara 8-128 (49.74 \pm 40.97). Sementara itu, untuk menekan munculnya mu tasi single step diperlukan MPI yang lebih rendah dan rentang MSW yang lebih sempit. Nilai MPI yang rendah mengindikasikan kemampuan yang lebih baik untuk mencegah pertumbuhan bakteri resistan atau mutan single step (Credito et al. 2010). Data AUC dari broiler yang diberi siprofloksasin dosis $8 \mathrm{mg} / \mathrm{kg}$ BB dan $10 \mathrm{mg} / \mathrm{kg}$ BB peroral, menunjukkan bahwa nilai AUC dosis tersebut berada di dalam rentang MSW. Berdasarkan hal tersebut menunjukkan dosis tersebut masih sangat memungkinkan pertumbuhan subpopulasi mutan resistan terhadap siprofloksasin. 
Tabel 2. Data farmakokinetik AUC, Cmaks, dan Tmaks siprofloksasin pada ayam broiler

\begin{tabular}{lccc}
\hline Parameter farmakokinetik & \multicolumn{3}{c}{ Dosis dan Rute } \\
\cline { 2 - 4 } & $\begin{array}{c}8 \mathrm{mg} / \mathrm{kg} \mathrm{BB} \mathrm{PO} \\
\text { (Anadón } \text { et al. 2001) }\end{array}$ & $\begin{array}{c}50 \mathrm{mg} / \mathrm{kg} \mathrm{BB} \mathrm{IV} \\
\text { (Ambarwati 2014) }\end{array}$ & $\begin{array}{c}10 \mathrm{mg} / \mathrm{kg} \text { BB PO } \\
\text { (Ivanova } \text { et al. 2017) }\end{array}$ \\
\hline AUC $(\mu \mathrm{g} . \mathrm{jam} / \mathrm{mL})$ & $12.21 \pm 1.22$ & 36.29 & $11.97 \pm 0.6$ \\
Cmaks $(\mu \mathrm{g} / \mathrm{mL})$ & $2.63 \pm 0.20$ & $15.294 \pm 1.34 \mu \mathrm{g} / \mathrm{mL}$ & $2.638 \pm \mathrm{mg} / \mathrm{mL}$ \\
Tmaks $(\mathrm{menit}$ ke) & $21.6 \pm 8.14$ & - & $39 \pm 0.17$ \\
\hline
\end{tabular}

Keterangan: AUC (Area Under Curve); Cmaks = Konsentrasi maksimal; Tmaks = waktu yang diperlukan untuk mencapai Cmaks

Dalam evaluasi dosis obat berkenaan dengan munculnya resistansi data KHM, MPC, MSW dan farmakokinetik sangat memegang peranan penting. Data ini sangat penting untuk melakukan penilaian risiko resistansi (EMA 2018). Pemberian antibiotik dengan dosis beradasarkan MPC juga harus sangat berhati-hati karena memerlukan dosis yang sangat tinggi sehingga dapat menimbulkan efek samping yang tidak diharapkan. Mengingat siprofloksasin merupakan antibiotik yang masuk dalam Highest Priority Critically Important bagi manusia maka sebaiknya tidak menggunakan siprofloksasin sebagai pilihan pertama di hewan produksi. Monitoring resistansi siprofloksasin beserta deteksi gen resistan siproflokasin dari hewan produksi sebaiknya dilakukan secara terus menerus sehingga bisa memberikan gambaran yang utuh mengenai prevalensi siprofloksasin dan dilanjutkan dengan penilaian risiko penggunaan siprofloksasin di hewan produksi.

\section{Kesimpulan}

Berdasarkan hasil uji MPC didapatkan nilai MPC siprofloksasin 4-64 $\mu \mathrm{g} / \mathrm{mL}(22.96 \pm 19.07$ $\mu \mathrm{g} / \mathrm{mL}$ ) dan terdapat satu isolat yang memiliki MPC $>256 \mu \mathrm{g} / \mathrm{mL}$. Hasil ini memberikan rentang MSW yang luas yaitu dengan batas bawah nilai KHM $0.25-2 \mu \mathrm{g} / \mathrm{mL}(0.55 \pm 0.37 \mu \mathrm{g} / \mathrm{mL})$ hingga batas atas $4-64 \mu \mathrm{g} / \mathrm{mL}(22.96 \pm 19.07 \mu \mathrm{g} / \mathrm{mL})$. Hasil ini memberikan nilai mutant prevention index(MPI) siprofloksasin pada E. coli yang lebar yaitu antara 8-128 (49.74 \pm 40.97$)$. Berdasarkan hasil pengkajian MPC ini dapat disimpulkan dapat bahwa dosis pemberian siprofloksasin pada hewan produksi memiliki rentang MSW yang cukup lebar sehingga memungkinkan timbulnya singlestep-mutant.

\section{Daftar Pustaka}

Ambarwati. (2014). Studi farmakokinetik siprofloksasin pada plasma, hati, ginjal, dan otot pada briler menggunakan kromatografi cair kinerja tinggi (KCKT). Fakultas Kedokteran Hewan Universitas Gadjah Mada, Yogyakarta

Anadón, A., Martínez-Larrañaga, M.R., Iturbe, J., Martínez, M.A., Díaz, M.J., Frejo, M.T., Martínez,M.(2001).Pharmacokinetics and residues of ciprofloxacin and its metabolites in broiler chickens. Res Vet Sci. Oct;71(2):101-9. https://doi. org/10.1053/rvsc.2001.0494

Berkhoff, H.A. and Vinal, C.A. (1986). Congo red medium to distinguish between invasive and non-invasive Escherichia coli pathogenic for poultry. Avian Dis. 30(1):117-131. https://10.2307/1590621

Blondeau, J.M. (2009). New concepts in antimicrobial susceptibility testing: the mutant prevention concentration and mutant selection window approach. Vet Dermatol. (20):383-396. doi. org/10.1111/j.1365-3164.2009.00856.x

Clinical Laboratory Standards Institute [CLSI]. (2016). M100S: Performance standards for antimicrobial susceptibility testing $26^{\text {th }}$ Ed. CLSI. USA. pp: 52-54, 196

Cai, Y., Li, R., Liang, B., Bai, N., Liu, Y., Wang, R. (2010). In vitro antimicrobial activities and mutant prevention concentration of colistin against Acinetobacter baumannii. Antimicrob Agents Chemother. 54(9):3998-3999. doi:10.1128/AAC.00264-10

Choi, M.J. and Ko, K.S. 2014. Mutant prevention concentration of colistin for Acinetobacter baumanii, Pseudomonas aeroginosa and 
Klebsiella pneumonia clinical isolat. $J$ Antimicrob Chemother. 69(1):275-277. doi. org/10.1093/jac/dkt315

Credito, K., Kosowska-Shick, K., Appelbaum, P.C. (2010). Mutant prevention concentration of four carbapenems against gram-negative rods. Antimicrob Agents Chemother. 54(6): 2692-2695. doi:10.1128/AAC.00033-10

Daoud, Z., Sokhn, E.S., Azar, E., Masri, K., Doron, S. (2014). Mutant prevention concentration of ciprofloxacin against urinary isolates of Escherichia coli and Klebsiella pneumonia. $J$ Infect Dev Ctries 8(2): 154-159. doi:10.3855/jidc.3164

Direktorat Jenderal Peternakan dan Kesehatan Hewan [DJPKH]. (2016). Indeks Obat Hewan Indonesia Ed. IX. Jakarta (ID): Kementerian Pertanian Republik Indonesia. pp. 58-599.

Drlica, K. (2003). The mutant selection window and antimicrobial resistance. J Antimicrob Chemother. August: 1-7.DOI: 10.1093/jac/ dkg269

European Medicine Agency [EMA]. (2018). Guideline on the assessment of the risk to public health from antimicrobial resistance due to the use of an antimicrobial veterinary medicinal product in food producing animals (Draft 2). Retrieved Oktober 01, 2018from www.ema.europa.eu/docs/ en gb/document library/scientific guideline/2018/07/WC500252679.pdf

Gebru, E., Choi, M.J., Lee S.J., Damte, D., Park, S.C. (2011). Mutant prevention concentration and mechanism of resistance in clinical isolat and enrofloxacin/ marbofloxacin-selected mutants of Escherichia coli of canine origin. J Med Microbiol. 60(Pt10):15121522. doi:10.1099/JMM.0.028654-0

Gianvecchio, C., Lozano, N.A., Henderson, C., Kalhori, P., Bullivant, A., Valencia, A., Su, L., Bello, G., Wong, M., Cook, E., Fuller, L., Neal III, J.B., Yeh, P.J. (2019). Variation in mutant prevention concentration. Front Microbiol. 10:42. doi:10.3389/ fmicb.2019.00042
Hansen, G.T, Zhao, X., Drlica, K., Blondeau, JM. (2006). Mutant prevention concentration for ciprofloxacin and levofloxacin with Pseudomonas aeruginosa. Int J Antimicob Agents 27: 120-124

Hindler, J.A, and Humphries, R.M. (2013). Colistin MIC variability by method contemporary clinical isolates of multidrug-resistant gram negative bacilli. JCM. 51(6):1676-1684. doi:10.1128/JCM.03385-12

Ivanova, S., Dimitrova, D., Petrichev, M. (2017). Pharmacokinetics of ciprofloxacin in broiler chickens after single intravenous and intraingluvial administration. Mac Vet Rev 40 (1): 67-72

Khan, G.J., Khan, R.A., Majeed, I., Siddiqui, F.A., Khan, S. (2015). Ciprofloxacin; the frequent use in poultry and its consequences on human health. Professional Med $J$ 22(1):001-005.

Marcusson, L.L., Olofsson, S.K., Lindgren, P.K., Cars, O., Hughes, D. (2005). Mutant prevention concentration of ciprofloxacin for urinary tract infection isolates Escherichia coli.J Antimicrob Chemother. 55:938-943. doi:10.1093/jac/dki136

Mouton, J.W., Dudley, M.N., Cars, O., Derendorf, H., Drusano, G.L. (2005). Standardization of pharmacokinetic/ pharmacodinamis (PK/ PD) terminology for anti-infective drugs: an update. J Antimicrob Chemother. 55:601607. doi.org/10.1093/jac/dki079

Randall, L.P, Cooles, S.W., Piddock, L.V.J, Woodward, M.J. (2004). Mutant Prevention concentration of ciprofloxacin for Salmonella enterica. J Antimicrob Chemother. 54: 688-691

Standar Nasional Indonesia [SNI]. 2008. SNI 2897 tentang Metode Pengujian Cemaran Mikroba dalam Daging, Telur, dan Susu, serta Hasil Olahannya. Jakarta (ID): Badan Standardisasi Nasional.

World Health Organization [WHO]. (2017). Critically important antimicrobials for human medicine - 5th rev. WHO. Switzerland. Licence: CC BY-NC-SA 3.0 IGO. Pp:12-37 